\title{
IMPACTOS NA IMPLANTAÇÃO DA FERRAMENTA 5S COMO AÇÃO INOVATIVA EM PROCESSOS EM MPE DA CONSTRUÇÃO CIVIL
}

Tanyra De Fátima Ferreira Do Amaral ${ }^{1}$

Vera Lúcia Tincani Osório ${ }^{2}$

\footnotetext{
${ }^{1}$ Faculdade de Ciências Aplicadas - UNICAMP / UNICAMP ( Universidade Estadual de Campinas )
}

${ }^{2}$ Universidade Federal do Rio Grande do Sul 


\section{IMPACTOS NA IMPLANTAÇÃO DA FERRAMENTA 5S COMO AÇÃO INOVATIVA EM PROCESSOS EM MPE DA CONSTRUÇÃO CIVIL}

Resumo: O estudo avaliou a implantação da ferramenta 5S, como ação inovativa de melhoria de processos, em empresas da construção civil, atendidas pelo Programa Agente Local de Inovação, utilizando como base o Radar da Inovação. As análises iniciais demonstraram que as alterações de processos ou de instalações, visando eficiência, qualidade, flexibilidade ou rapidez no atendimento, não faziam parte da rotina empresarial, refletindo na baixa pontuação da dimensão Processos. Ao final do primeiro Ciclo, as ações executadas impactaram positivamente, sendo que uma das empresas (E1) avançou de 2,3 para 3,7. O descarte otimizou mais espaço e a venda de materiais em desuso gerou receita, houve expansão das ações para outros setores e agilização no atendimento aos clientes. Tais resultados evidenciam que ações simples, no curto prazo, viabilizam a redução dos custos e o aumento da receita, como estratégias de sobrevivência e de aumento da competitividade, frente a grave crise econômica.

Palavras-chave: Construção civil. Inovação em processos. Ferramenta 5S. Programa ALI. 


\section{Introdução}

A construção civil, segundo Cataldo (2016), representa em torno de $9 \%$ do Produto Interno Bruto (PIB) nacional, e 2015 foi um dos piores anos para a economia e para este segmento no Brasil. Houve retração de 3,6\% do setor, com a eliminação de 500 mil postos de trabalho nas empresas deste ramo, o que reflete em menos consumo no mercado, de modo geral.

Diante deste cenário, as construtoras e incorporadoras estão buscando por estratégias de mercado, tais como ajustes na composição de equipes (...) e análise estratégica de estoque de terrenos, e vêm adotando redução de custo e investimento em planejamento e produtividade (CONSTRUÇÃO MERCADO, 2015).

De modo a contribuir com o desenvolvimento local das micro e pequenas empresas (MPE), o Programa Agentes Locais de Inovação (ALI) tem por objetivo fomentar a prática continuada de ações de inovação, utilizando como estratégia a orientação proativa, gratuita e personalizada às empresas atendidas, acompanhadas por até 30 meses por bolsistas EXP-SB do Conselho Nacional de Desenvolvimento Científico e Tecnológico (CNPq), capacitados pelo Serviço Brasileiro de Apoio às Micro e Pequenas Empresas (SEBRAE). O compromisso dos atores do Programa ALI é o de levar soluções de inovação imediatas e tangíveis às empresas (MANUAL DO PROGRAMA AGENTES LOCAIS DE INOVAÇÃO, 2015).

Neste contexto, foram selecionadas para o estudo quatro empresas da construção civil, localizadas em Mogi Mirim e Mogi Guaçu, interior de São Paulo, participantes do primeiro Programa ALI implantado na região de São João da Boa Vista. O objetivo do trabalho foi o de avaliar os resultados obtidos por essas empresas, em decorrência da implantação da ferramenta $5 \mathrm{~S}$, como uma ação inovativa, voltada para a melhoria dos processos internos, na busca de maior eficiência, maior qualidade ou um tempo de resposta menor, possibilitando aumentar a competitividade empresarial, frente a um momento de grave crise econômica no país.

\section{Referencial Teórico}

\subsection{O Mercado de Construção Civil}

Entre os anos de 2015 e 2016, a construção civil esteve bastante afetada pelo sistema econômico. Há uma grande quantidade de imóveis sem estar liquidados devido à falta de crédito. Há indicativos de que o próprio setor contribuiu para a crise instalada na construção civil. Isto porque construtoras e empreiteiras ofertaram em excesso imóveis e, posteriormente, houve estagnação nos lançamentos (AMORIM, 2015).

O SEBRAE (2016), através da análise do varejo de lojas de materiais de construção, chegou à conclusão de que a gestão de processos, a gestão de estoque e o layout da loja são apresentados compõem os fatores-chave de sucesso no varejo das empresas de materiais de construção, questão destacada no objetivo deste estudo.

\subsection{Inovação e Organizações}


A inovação é essencial para uma empresa sobreviver num mercado cada vez mais competitivo. O processo de inovação envolve criar novos modelos de negócios, novas formas de atender às necessidades dos consumidores, novos processos, dentre outros (FNQ, 2008).

Luiz Malta sinaliza, no site Contábeis (2015), que a inovação é importante para se diferenciar em uma economia ruim. Salienta ainda que mudanças simples nas empresas, em processos, possibilitam otimização de receita, com redução de custo.

Segundo o Manual de Oslo, "uma inovação é a implementação de um (...) processo (...) nas práticas de negócios, na organização do local de trabalho ou nas relações externas", ou seja, que a empresa apresente produto, processo, método de marketing ou organizacional novos ou significativamente melhorados. Sua finalidade é melhorar o desempenho da organização, através de mudanças planejadas. Drucker (1973) apud Villela (2013) chegou a considerar a inovação a principal competência em uma organização. (MANUAL DE OSLO, 2005).

Em se tratando de inovação em processos, estes devem ser identificados, analisados e melhorados continuamente, em busca do atendimento das demandas dos clientes (HARRINGTON, 1993; GONÇALVES, 2000a apud DÁVILA et. al, [2008 ou 2010]). A inovação, aplicada nos processos, busca a melhoria da qualidade dos bens e serviços, a redução de tempos e custos, dentre outros objetivos (DÁ VILA et al, [2008 ou 2010]).

\subsection{Programa ALI e o Radar da Inovação}

O Programa ALI foi criado, em âmbito nacional, através de um acordo de cooperação técnica entre o SEBRAE e o CNPq, com o intuito de promover a inovação nas micro e pequenas empresas. Os agentes selecionados passam por uma capacitação do SEBRAE, e buscam aproximar as empresas com provedores de solução. Objetiva promover, a partir de orientação proativa, gratuita e personalizada, a prática continuada de ações de inovação das empresas. Possui caráter diferencial e estratégico de competitividade para os pequenos negócios.

Os empreendimentos recebem a visita dos agentes, os quais, em conjunto com os empresários, avaliam as condições atuais das empresas frente à inovação e buscam soluções e respostas às demandas do negócio que impactam diretamente na gestão empresarial, em melhorias de produtos, processos e na identificação de novos nichos de mercado para seus produtos, fomentando a gestão da inovação nos negócios (PORTAL SEBRAE, [2014?]).

O trabalho de campo dos agentes utiliza o Radar da Inovação como ferramenta de diagnóstico para de medir o Grau de Inovação das empresas assistidas. A metodologia do referido Programa se baseia num fluxo de trabalho dividido em ciclos. São previstos 3 ciclos durante o Programa ALI, sendo que o fim de um ciclo representa a conclusão de três ou mais ações do Plano de Ação. Todas as informações coletadas são depositadas no Sistema ALI, recurso desenvolvido para armazenar e gerenciar os dados do Programa.

A metodologia do Radar da Inovação foi desenvolvida pela Bachmann \& Associados, para que o SEBRAE dispusesse de uma avalição objetiva, capaz de tornar as pequenas empresas mais inovadoras. Tal Radar coloca o foco na capacidade de o empresário inovar, não avaliando o ambiente social ou um sistema de inovação onde estas empresas, eventualmente, estão inseridas. As informações geradas pela aplicação desta ferramenta é uma referência útil para definir planos de ação que desenvolvam cada vez mais a capacidade de inovar nas MPE. Os dados gerados pela sua aplicação têm vantagens, ao permitir uma mensuração quantitativa, por

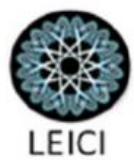


apresentar baixa subjetividade, indicar o direcionamento para melhorias e permitir avaliações setoriais, regionais e históricas (SEBRAE \& BACHMANN, 2011). Tendo como pressuposto que a inovação não é um evento ou fato isolado, mas resultante de um processo, o Radar da Inovação avalia a maturidade de inovação nas pequenas empresas, focando seus processos, resultados e relevância do conhecimento como ferramentas fundamentais para a competitividade empresarial. Com estas bases, as empresas que têm práticas mais estruturadas para obter inovação (ou seja, possuem uma ação sistemática), alcançam maior escore na avaliação do Radar da Inovação, o qual utiliza, para esta avaliação, 13 dimensões. A determinação do Radar da Inovação está em três pilares: o que avaliar, como medir e o período de tempo a se considerar, conforme Quadro 1 (BACHMANN \& ASSOCIADOS, 2014).

\section{Quadro 1: Classificação das empresas quanto ao Grau de Inovação}

\begin{tabular}{|l|l|c|}
\hline \multicolumn{1}{|c|}{ CLASSIFICAÇÃO } & \multicolumn{1}{|c|}{ DEFINIÇÃO } & GRAU DE INOVAÇÃO \\
\hline Inovadora Sistêmica & Pratica sistematicamente a gestão da inovação. & $>4$ \\
\hline Inovadora Ocasional & Inovou, porém não há sistematização do processo. & $<3$ e >4 \\
\hline Pouco ou nada Inovadora & Inova pouco ou não inova. & $>1$ e $<3$ \\
\hline
\end{tabular}

Fonte: Silva Néto, Ana Teresa da. Mensuração do Grau de Inovação em Micro e Pequenas Empresas do Estado de Sergipe. Dissertação de mestrado da Universidade Federal de Sergipe. Sergipe 2012, apud Bachmann \& Associados. 2014.

Nota: Se a pontuação do Grau de Inovação for 1, a empresa não é inovadora.

O horizonte temporal que abrange a avaliação do Radar da Inovação considera os 3 ultimos anos (BACHMANN \& ASSOCIADOS, 2014). Portanto, uma empresa ter obtido o mesmo valor do ciclo 0 para o ciclo 1 não implica que ela não evoluiu, bem como o fato de ter havido uma redução nestes valores não significa necessariamente que a empresa piorou, mas sim que pode ter havido a adoção de uma ação nova ao passo que outra mais antiga passou a não pertencer ao período do novo ciclo (para o primeiro caso), e não ter sido implementada nova ação quando outra não mais compôs o período do ciclo 1 (no segundo caso).

Especificamente, neste estudo, para analisar os impactos gerados nas empresas, em decorrência da adoção da ferramenta 5S, foram utilizadas duas dimensões, Processo e Organização, cujos indicadores avaliados na metodologia do Radar da Inovação apresentam relação direta, com as ações inovativas da ferramenta, em Processos e, indiretamente, na estrutura da empresa em termos de reorganização na dimensão Organização (Tabela X).

Tabela X - artigo Dimensões Processo e Organização, descrição e indicadores

\begin{tabular}{|l|l|l|}
\hline Dimensão & \multicolumn{1}{|c|}{ Descrição } & \multicolumn{1}{|c|}{ Indicadores } \\
\hline \multirow{4}{*}{ Processos } & $\begin{array}{l}\text { Configurações das atividades usadas na } \\
\text { condução das operações internas à empresa. A } \\
\text { inovação, pressupõe o reprojeto de seus } \\
\text { processos para buscar maior eficiência, maior } \\
\text { qualidade ou um tempo de ciclo menor }\end{array}$ & $\begin{array}{l}\text { Gestão; (3) Certificações; (4) Software de } \\
\text { e (6) Gestão de Resíduos }\end{array}$ \\
\hline \multirow{3}{*}{ Organização } & $\begin{array}{l}\text { Modo como a empresa está estruturada, quais as } \\
\text { parcerias estabelecidas, e e o papel e e } \\
\text { responsabilidade dos colaboradores }\end{array}$ & (1) Reorganização; (2) Parcerias; (3) Visão \\
\hline
\end{tabular}

Fonte: Devolutiva SistemALI (2016) 


\subsection{O Modelo de Qualidade 5S}

O Modelo de Qualidade 5S é uma filosofia que surgiu no Japão na década de 60 e advém de cinco atividades sequenciais e cíclicas iniciadas pela letra "S", em japonês: SEIRI (Senso de Utilização), SEITON (Senso de Organização), SEISO (Senso de Limpeza), SEIKETSU (Senso de Saúde), e SHITSUKE (Senso de Disciplina), e seu objetivo é trazer melhoria ao ambiente de trabalho, tanto físico, lógico, quanto mental, com base educativa. Ele prepara as pessoas para observarem e terem atitudes quanto ao desperdício, desorganização e sujeira, como sendo fatores que contribuem para o adoecimento e conflitos. O empresário deve ser o principal incentivador do processo de implementação da metodologia 5S, exercendo papel de liderança para obter os melhores resultados (PLURIO, 2014).

As principais dimensões do Radar de Inovação impactadas com esta ação foram Processos (modificação na estocagem de produtos e implantação de nova prática de gestão) e Organização (com a nova prática de organização do estoque, as atividades dos colaboradores sofreram alteração, tais como a rotina de recebimento e alocação adequada de produtos).

\section{Procedimentos Metodológicos}

A metodologia utilizada no estudo orientou-se pelos princípios da pesquisa científica definida como uma "atividade básica das ciências na indagação e descoberta da realidade", provinda de um "questionamento sistemático crítico e criativo, mais a intervenção competente na realidade" (MINAYO, 1993 apud SILVA E MENEZES, 2005). Ela se caracteriza como uma pesquisa aplicada, por gerar conhecimento dirigido à solução de problemas encontrados na realidade (GIL, 1999, LAKATOS; MARCONI, 1993 apud SILVA; MENEZES, 2005), a partir da atuação em campo de um agente local de inovação.

Para o desenvolvimento metodológico optou-se por combinar as abordagens qualitativas e quantitativas, a partir dos dados e informações produzidos pelo Programa ALI, no período de 2015 a 2016, referente às quatro empresas do setor comercial da construção civil, localizadas nas cidades de Mogi Mirim e Mogi Guaçu, que implantaram a ferramenta de Gestão da Qualidade, denominada 5S, no seu primeiro Plano de Ação.

Os dados quantitativos de cada unidade empresarial foram tratados e sistematizados, com o intuito de criar comparabilidade quanto ao desempenho do Grau de Inovação, utilizando, para isso, as informações do Radar da Inovação, aplicado após a adesão das empresas ao Programa ALI e ao final do primeiro Ciclo, que em média teve a duração de 6 a 8 meses.

A parte qualitativa do estudo considerou as informações da Ficha de Cadastro das empresas, os registros do agente durante o período de acompanhamento do Plano de Ação e as devolutivas com os empresários, momentos que garantiram um olhar reflexivo sobre o Grau de Inovação, o desempenho das empresas e a relação com as ações inovativas executadas.

A utilização dos dados e informação de natureza qualiquantitativa se justifica por serem complementares, ao se reconhecer que há uma interação dinâmica na realidade estudada, nas quais as atitudes e comportamentos dos empresários são determinantes para o processo da criação de uma cultura inovativa, considerando que o Radar da Inovação, segundo SEBRAE \& Bachmann (2011), coloca foco nas empresas (capacidade do empresário inovar) e não avalia o ambiente externo (social ou de um sistema de inovação) no qual essas empresas estão inseridas.
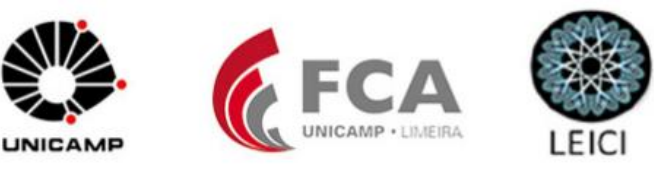


\section{Apresentação, Análise e Discussão dos Resultados}

As quatro empresas estudadas neste artigo pertencem à microrregião da Baixa Mogiana, a Leste do estado de São Paulo (duas em Mogi Mirim e duas em Mogi Guaçu). São enquadradas como Empresa de Pequeno Porte, atuam no comércio da construção civil com pisos e revestimentos e materiais hidráulicos e elétricos. Das 4 empresas estudadas, três são do mesmo grupo familiar (E2, E3 e E4) e, apesar de terem o mesmo gestor responsável, foram tratadas no Programa ALI como empresas distintas quanto à avaliação, a proposta de ações e de análise dos resultados, envolvendo o Radar da Inovação. As empresas selecionadas têm em comum a implantação do $5 \mathrm{~S}$ em seus Planos de Ação no primeiro ciclo do Programa ALI.

No momento inicial do Programa constatou-se a baixa pontuação da dimensão Processos e a ausência de programação contemplando ações com essa finalidade pelo empresário. Esta situação, em certa medida, limitava a capacidade do negócio em reduzir custos e otimizar receitas, impactando negativamente nos níveis de competitividade empresarial, frente a um quadro de instabilidade econômica. Tal condição provocava a retração das vendas, a demanda por preços menores, a pressão dos concorrentes e a limitação de acesso a capital, exigindo que o empresário priorizasse ações de diminuição de custos ou diferenciação do produto, visando garantir a sobrevivência da empresa e se preparar para voltar a crescer e aumentar sua participação nos negócios, na retomada do crescimento econômico.

Com a validação das ações inovativas, a ferramenta $5 \mathrm{~S}$ foi implantada a pelas empresas, num período que variou de 6 a 8 meses. Ao final do $1^{\circ}$ Ciclo, as análises comparativas das dimensões Processos e Organização trouxeram leituras importantes para avaliar os resultados alcançados, sob o ponto de vista quantitativo e qualitativo.

Processos é a dimensão em que as empresas apresentam os menores valores no momento inicial, caracterizando-se como pouco ou nada inovadoras, ou seja, as ações para alterar os processos ou instalações, visando obter maior eficiência, qualidade, flexibilidade ou rapidez no atendimento, eram incipientes na rotina empresarial.

E1, em Processos, alcança os melhores resultados (de 2,3 passa para 3,7);

E2, apesar de implantar ações da ferramenta 5S, permaneceu no mesmo patamar (1,3 pontos). Isto ocorreu pelo fato que outras ações, ao final do primeiro Ciclo, tinham ultrapassado os 3 anos, entretanto, se a empresa não tivesse realizado essas ações inovativas, teria involuido no seu escore final;

E3 e E4 apresentaram a mesma evolução. Houve melhoria, mas ainda assim o escore final ficou em 2,0, configurando-se ainda como empresas limitadas na execução de ações inovativas para melhoria dos processos.

Em Organização, observa-se um nítido contraste nas pontuações iniciais e finais nesta dimensão, destacando-se a E1 como uma empresa inovadora sistêmica.

E1 apresenta um escore inicial de 4,3 (R0) e, ao final, alcança a maior pontuação do Radar da Inovação $(5,0)$, indicando que ações voltadas a reorganização interna, parcerias, visão externa e estratégia competitiva estão internalizadas no seu ambiente empresarial.

E2, E3 e E4 tinham poucas ações em termos de estrutura organizacional, suas parcerias e a responsabilidade dos colaboradores. Sua pontuação inicial foi de 1,3, mas chega ao final do primeiro ciclo com 3 pontos, refletindo esforço para a execução das ações nesta perspectiva.

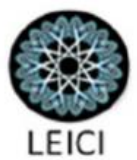


Gráfico X - Grau de Inovação daS dimensões Processos e Organização (R0 e R1)

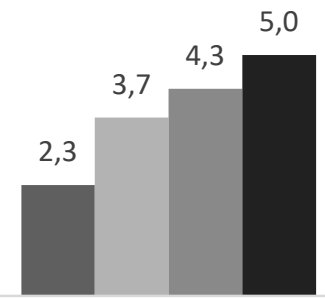

E1

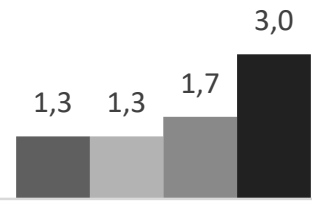

E2

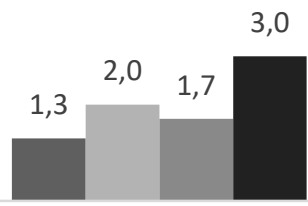

E3

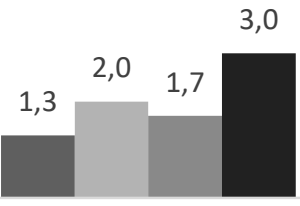

E4

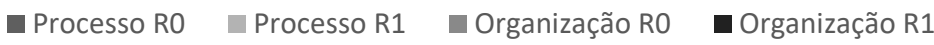

Fonte: Sistema ALI/Radar da Inovação/Devolutiva, 2016 e 2017

Para melhor caracterizar os resultados alcançados são listados alguns registros feitos durante o processo de acompanhamento da execução do Plano de Ação constando, no geral, que as ações de $5 \mathrm{~S}$ promoveram melhorias observadas nas empresas, conforme o Quadro X:

Quadro X: Resultados das ações da ferramenta 5S

\begin{tabular}{|c|c|c|c|c|}
\hline Resultados das ações implantadas & E1 & E2 & E3 & E4 \\
\hline $\begin{array}{l}\text { Ampliação da loja através de melhor disposição dos espaços subutilizados e ao serem } \\
\text { descartados produtos ociosos }\end{array}$ & & $\mathrm{X}$ & & \\
\hline Redução da quantidade de material em desuso e maior disponibilidade de espaço & $X$ & $\mathrm{X}$ & $\mathrm{X}$ & $\mathrm{X}$ \\
\hline Geração de receita com venda material fora de linha e de mostruário & $\mathrm{X}$ & $\mathrm{X}$ & $\mathrm{X}$ & $\mathrm{X}$ \\
\hline Expansão da ferramenta 5S para outros setores não previstos incialmente & $\mathrm{X}$ & & & \\
\hline Redução do risco de acidentes com animais peçonhentos no ambiente da empresa & $\mathrm{X}$ & & & \\
\hline Ampliação do espaço visual para divulgação de parcerias & & $\mathrm{X}$ & & \\
\hline Rapidez no atendimento decorrente da organização de produtos em prateleiras & & $\mathrm{X}$ & $\mathrm{X}$ & $\mathrm{X}$ \\
\hline
\end{tabular}

Fonte: Registro dos acompanhamentos da execução do Plano de Ação no Programa ALI (2016).

\section{Considerações Finais}

O estudo possibilitou avaliar os resultados alcançados pelas empresas da construção civil em função da implantação da ferramenta $5 \mathrm{~S}$, como uma importante ação inovativa de melhoria de processos, atendidas pelo Programa ALI. O uso dos dados disponíveis na Ficha Cadastral, no Radar da Inovação e no Plano de Ação, bem como as informações registradas pelo agente nos momentos de acompanhamento e de devolutivas realizadas junto ao empresário, combinando dados qualiquantitativos, foram suficientes para compor o material necessário.

As análises no momento inicial retrataram que as ações para alterar os processos ou instalações, visando obter maior eficiência, qualidade, flexibilidade ou rapidez no atendimento, não faziam parte da rotina empresarial como ações contínuas. Por isso, o Grau de Inovação da 
dimensão Processos era inferior a 3,0, condição pouco ou nada inovadora. Entretanto, ao final do primeiro Ciclo, as ações executadas impactaram positivamente, sendo que uma das empresas (E1) evoluiu de 2,3 para 3,7 nessa dimensão. Com a aplicação das ações da ferramenta 5S, as empresas passaram a dispor de mais espaço pela redução da quantidade de material em desuso, e a venda de parte desse material possibilitou a geração de receita. Uma empresa expandiu as ações para outros setores, não previstos incialmente, e, nas outras três, a organização dos materiais/produtos agilizou o atendimento aos clientes. Uma empresa, inclusive, se beneficiou da organização do espaço visual para estabelecer importante parceria promocional com fornecedor.

A indicação para futuros estudos seria no sentido de analisar com maior detalhamento os impactos da aplicação da ferramenta $5 \mathrm{~S}$ na produtividade da equipe, na redução de custos e na lucratividade da empresa, como aperfeiçoamento da gestão empresarial subsidiando a tomada de decisão baseada em indicadores.

\section{REFERENCIAS}

AMORIM, L. Construção civil vive crise sem precedentes no Brasil. Exame.com. 2015. Disponível em: 〈http://exame.abril.com.br/revista-exame/a-crise-e-a-crise-da-construcao/>. Acesso em: 10 jan. 2017.

BACHMANN \& ASSOCIADOS; SEBRAE. Atualização dos formulários para a determinação do Radar da Inovação do Programa ALI - Relatório Técnico. Curitiba, 2014.

CÂMARA BRASILEIRA DA INDÚSTRIA DA CONSTRUÇÃO. Banco de dados. Disponível em: <http://www.cbicdados.com.br/home/>. Acesso em: 08 jan. 2017.

CATALDO, B. Construção civil alinha propostas para retomada da economia. Disponível em: < http://g1.globo.com/economia/blog/beth-cataldo/post/construcao-civil-alinha-propostaspara-retomada-da-economia.html>. Acesso em: 10 nov. 2016.

CONSELHO NACIONAL DE DESENVOLVIMENTO CIENTÍFICO E TECNOLÓGICO. ALI - Agentes Locais de Inovação. Disponível em: 〈http://cnpq.br/apresentacao-ali >. Acesso em: 13 jan. 2017.

CONSTRUÇÃO MERCADO. Negócios de incorporação e construção. É na crise que se cresce. Editorial. Edição 164.2015 .2 Disponível em: 
<http://construcaomercado.pini.com.br/negocios-incorporacao-construcao/164/e-na-crise-quese-cresce-338799-1.aspx >. Acesso em: 10 nov. 2016.

CONTÁBEIS. O portal da profissão contábil. Diferenciais das pequenas empresas podem ser saídas para driblar crise. 2015. Disponível em: $<$ http://www.contabeis.com.br/noticias/24074/diferenciais-das-pequenas-empresas-podemser-saidas-para-driblar-crise/>. Acesso em: 07 nov. 2016.

DÁVILA, G. A.; LEOCÁDIO, L.; VARVAKIS, G. Inovação e Gerenciamento de Processos: Uma análise baseada na Gestão do Conhecimento. Disponível em $<$ http://www.ngs.ufsc.br/wpcontent/uploads/2010/06/2008_DataGramaZero_Inovacao_GP.pdf>. Acesso em 30 abr. 2017.

FNQ. A importância da inovação para a sobrevivência das organizações. Disponível em: $<$ http://www.fnq.org.br/informe-se/artigos-e-entrevistas/entrevistas/a-importancia-dainovacao-para-a-sobrevivencia-das-organizacoes>. Acesso em: 13 jan. 2017.

IBGE - INSTITUTO BRASILEIRO DE GEOGRAFIA E ESTATÍSTICA. Sistema Nacional de Pesquisa de Custos e Índices da Construção Civil. 2016. Disponível em: $<$ http://www.ibge.gov.br/home/estatistica/pesquisas/pesquisa_resultados.php?id_pesquisa=53 >. Acesso em: 10 nov. 2016.

GOVERnO DE MOGI MIRIM. A cidade. Mogi Mirim. Cidade Simpatia. Disponível em: <http://www.mogimirim.sp.gov.br/acidade>. Acesso em 15 ago. 2016.

OCDE. Manual de Oslo. Diretrizes para coleta e interpretação de dados sobre inovação. $3^{\mathrm{a}}$ Ed. Tradução: FINEP, 2005.

OLIVEIRA, R. S. S., et al. Proposta de Aplicação da Metodologia 5S: um estudo de caso em uma empresa de manutenção de motocicletas no Cariri paraibano. XXXV Encontro Nacional de Engenharia de Produção. Fortaleza, CE, Brasil. Encontro 2015.

PETRY, R. Conheça startups que têm inovado o mercado imobiliário. Construção Mercado. Negócios de incorporação e construção. Edição 179. Junho/2016. Disponível em: 〈http://construcaomercado.pini.com.br/negocios-incorporacao-construcao/179/conhecastartups-que-tem-inovado-o-mercado-imobiliario-371115-1.aspx > . Acesso em: 07 nov. 2016.

PLURIO. Modelo de Qualidade 5S como cultura organizacional. Disponível em: $<$ https://plurio.com/pt/blog/modelo-de-qualidade-5s-como-cultura-organizacional/>. Acesso em: 13 jan. 2017.

PREFEITURA DE MOGI GUAÇU. A cidade. Disponível em: <http://www.mogiguacu.sp.gov.br/v2/cidade.php >. Acesso em 18 mar. 2017. 
PRESIDÊNCIA DA REPÚBLICA. Casa Civil. Subchefia para Assuntos Jurídicos. Lei complementar $\mathrm{n}^{\mathbf{0}} \mathbf{1 2 3}$, de 14 de dezembro de 2006. Disponível em: <http://www.planalto.gov.br/ccivil_03/leis/LCP/Lcp123.htm>. Acesso em 20 mar. 2017.

SEBRAE. Dez fatores-chave de sucesso no varejo de materiais de construção. Artigos. Disponível em: <https://sebrae.com.br/sites/PortalSebrae/artigos/dez-fatores-chave-desucesso-no-varejo-de-materiais-deconstrucao,00a7152f5f3c3510VgnVCM1000004c00210aRCRD>. Acesso em: 09 nov. 2016.

SEBRAE. Manual do Programa Agentes Locais De Inovação - ALI. Serviço Brasileiro de Apoio às Micro e Pequenas Empresas - SEBRAE. 2015.

SEBRAE. Participação das Micro e Pequenas Empresas na Economia Brasileira: Relatório Executivo. Brasília: SEBRAE, 2015.

SEBRAE. Programa ALI ajuda a implantar práticas inovadoras gratuitamente no seu negócio. Disponível em: <http://www.sebrae.com.br/sites/PortalSebrae/Programas/agenteslocais-de-inovacao-receba-o-sebrae-na-suaempresa,8f51d53342603410VgnVCM100000b272010aRCRD>. Acesso em: 13 jan. 2017.

SEBRAE. Sistema SEBRAE - Direcionamento Estratégico 2013-2022. Brasília: SEBRAE, 2012.

SEBRAE. Sistema SEBRAE - Diretrizes para Atuação do Sistema SEBRAE em Acesso à Inovação e Tecnologia. Brasília: SEBRAE, 2007.

SILVA, E. L; MENEZES, E. M. Metodologia da pesquisa e elaboração de dissertação. 4. Ed. Ver. Atual. Florianópolis: UFSC, 2005.

SILVA NETO, A. T.; TEIXEIRA, R. M. Mensuração do grau de inovação de micro e pequenas empresas: estudo em empresas da cadeia têxtil-confecção em Sergipe RAI: Revista de Administração e Inovação, v. 8, n. 3, p. 205-229, 2011.

VILLELA, C. S. S. Inovação organizacional: uma proposta de método para a inovação sistemática. 2013. 268f. Tese (Doutorado em Engenharia de Produção) - Universidade Federal de Santa Catarina, Florianópolis, 2013. 